\title{
¿Causes and Consequences of Sea Ice Initialization Shock in Coupled NWP Hindcasts with the GC2 Climate Model
}

\author{
T. C. JOHNS, ${ }^{a}$ E. W. BLOCKLEY, ${ }^{a}$ AND J. K. RIDLEY ${ }^{a}$ \\ ${ }^{\mathrm{a}}$ Met Office Hadley Centre, Exeter, United Kingdom
}

(Manuscript received 23 October 2020, in final form 15 March 2021)

\begin{abstract}
We present a coupled retrospective forecast (hindcast) study using the Met Office Global Coupled Model, version 2 (GC2), in which we identify and mitigate causes of initialization shock that lead to rapid error growth in sea ice forecasts. Sea ice state variables and volume budget terms as a function of forecast lead time are evaluated relative to analyses from an uncoupled Met Office ocean-sea ice analysis system [Forecast Ocean Assimilation Model, version 13 (FOAMv13)]. Two sources of initialization shock are highlighted and addressed, both of which are related to effective differences in physics between the analysis system and coupled forecast model. The primary shock to sea ice state variables arises from the use of a salinity-independent freezing temperature for seawater in GC2 as opposed to a salinity-dependent formulation in FOAMv13. A secondary effect arises from differences in the sea ice roughness and hence air-ice drag in the GC2 forecast model compared to the FOAMv13 analysis system. Generalizing from the findings of this study, we suggest that using nonnative analyses as initial conditions for coupled numerical weather prediction (NWP) studies will likely make them prone to initialization shock in some model components, to the detriment of forecast skill. To reduce the undesirable impacts of initialization shock on short-range forecast skill noted in this study we would therefore recommend the use of initial conditions (analyses) physically consistent with the native model components of the coupled forecast model, a native coupled analysis likely being the optimal initialization method.
\end{abstract}

KEYWORDS: Sea ice; Hindcasts; Numerical weather prediction/forecasting; Short-range prediction; Coupled models; Model initialization; Model evaluation/performance; Climate models

\section{Introduction}

Numerical weather prediction (NWP) models conventionally consist of an atmospheric model (usually with an embedded or coupled land surface model) driven with specified surface boundary conditions over the ocean and sea ice. Persisted sea surface temperatures (SSTs) and sea ice fractional coverage through the forecast, or persisted anomalies with respect to a seasonally varying climatology, are typically used as the boundary conditions for ocean and sea ice surfaces.

Over recent years, interest has increased in the potential for fully coupled atmosphere-land-ocean-sea ice models to advance skill on NWP time scales and there is growing evidence of benefits in both atmospheric and ocean-ice forecast applications on forecast time scales from days to weeks (Belcher et al. 2015; Brassington et al. 2015; Haiden et al. 2017; Smith et al. 2018). The mechanisms by which skill may be enhanced relative to conventional (uncoupled) NWP systems are well described by Smith et al. (2018) and include better representation of the evolution of sea surface temperature and sea ice conditions affecting local weather (Pellerin et al. 2004; Smith et al. 2013), of the air-sea interaction processes involved in tropical cyclones (Smith et al. 2018; Vellinga et al. 2020), and

¿ Denotes content that is immediately available upon publication as open access.

Johns: Retired.

Corresponding author: Ed Blockley, ed.blockley@metoffice.gov.uk improved representation of larger-scale modes of atmospheric variability such as the Madden-Julian oscillation in which interactive air-sea coupling may increase predictability (Shelly et al. 2014).

On the regional scale of the Gulf of St. Lawrence region Pellerin et al. (2004) and Smith et al. (2013) clearly demonstrated benefits to atmosphere-ocean-sea ice prediction-both in case studies and operational contexts-from an accurate coupled representation of air-sea ice exchanges at high latitudes. Improving short-range sea ice forecasts in regions and seasons where sea ice is prominent has the potential to benefit seasonal and climate model performance, for example via improved teleconnections from polar regions to midlatitudes (Jung et al. 2014). Sea ice may also remotely impact the severity of European and North American winters through planetary wave effects (Handorf et al. 2015; Overland 2016) although the degree to which variations in Arctic sea ice directly influence rather than being correlated with midlatitude weather is an active area of research (Blackport et al. 2019; Blackport and Screen 2020). Sea ice may itself be affected by shifting patterns associated with El Niño (Hu et al. 2016).

The topic of short-range to seasonal forecasting systems for the polar regions has gained an increasing profile in the meteorological community in conjunction with the International Year of Polar Prediction activities (Goessling et al. 2016; Jung et al. 2016), organized under the auspices of the World Meteorological Organization.

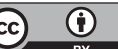
This article is licensed under a Creative Commons Attribution 4.0 license (http://creativecommons.org/ licenses/by/4.0/). 
At the Met Office, coupled NWP forecast suites have been run routinely for several years both for research purposes and to provide operational output specifically for the Copernicus Programme's Marine Environmental Monitoring Service (https://marine.copernicus.eu/) in the form of global ocean analysis and forecast products (described in https:// resources.marine.copernicus.eu/documents/QUID/CMEMSGLO-QUID-001-015.pdf). Coupled NWP suites have not yet replaced conventional NWP suites for the general production of global weather, marine, and sea ice forecast products but research directed toward that end over the past decade has included running retrospective coupled atmosphere-ocean-sea ice global forecasts (hindcasts) experimentally in NWP mode, and exploring the ability of coupled NWP to compete with uncoupled NWP setups in terms of large-scale forecast skill and the representation of weather phenomena (Shelly et al. 2014; Vellinga et al. 2020). Coupled NWP case studies have also formed one component within a broader suite of atmosphere and coupled model tests used to compile evidence that informs the development of the MetUM for use in NWP, seasonal forecasting, decadal and long-term climate prediction applications (Brown et al. 2012).

A key issue in general for coupled NWP hindcasts is initializing the model components, specifically finding an initialization method for the atmosphere, ocean and sea ice that avoids rapid divergence from the initial state in the coupled forecast. Even if a global coupled NWP model is apparently "well-initialized" in the sense that the initial states of the model components are each separately realistic with respect to observational data, a degree of initialization shock can still occur at the start of the coupled forecast for various reasons including inherent imbalances in the coupled model state arising from the model's particular characteristics, the use of nonnative analyses (relative to the coupled forecast model) as a basis for the initialization, or from turning off at the start of the coupled forecast the data assimilation increments (or bias corrections) that are in effect part of the analysis (Mulholland et al. 2015).

Here, we investigate how well a relatively simple coupled initialization process works in coupled NWP hindcast case studies using initial conditions (analyses) derived from uncoupled data assimilation (DA) systems. We look at this question using a specific Met Office coupled model version: Global Coupled version 2 (GC2) (Williams et al. 2015). The analyses used for initialization are taken from systems with component model science configurations bearing similarities to the GC2 forecast model, but not completely native to it. In the light of the study of Mulholland et al. (2015) we would expect some initialization shock at the start of our forecasts due to the nonnative analysis effect, but it is not clear whether to expect any initialization shock that occurs to be of major or only minor significance relative to the underlying systematic error growth.

The methodology we describe could be used to investigate systematic errors in many atmosphere and ocean variables but we focus here solely on forecast errors in sea ice state and volume budget terms, as measured against corresponding analyses. Our prime motivation for the focus on sea ice is that physical interactions between sea ice, atmosphere, and ocean on fast time scales mean that sea ice is a potential area for significant improvement in coupled as opposed to uncoupled NWP forecasts (Pellerin et al. 2004; Smith et al. 2013). A further motivation is to seek insights into the origins of systematic GC2 model errors related to processes of air-sea ice interaction, with the ultimate goal of identifying potential improvements both to the sea ice data assimilation system and coupled model itself. In the latter case, this would have benefits not just for short-range forecasting purposes but also for seasonal and climate predictions conducted with future releases of the Met Office Global Coupled model in the seamless prediction context (Brown et al. 2012).

Our coupled NWP experiments explore the 1-15-day forecast range and we take a deterministic approach to verification of the model performance although, with suitable changes to the experimental design and verification methods, they could potentially be extended to longer time scales and ensemblebased verification.

The remainder of the manuscript is organized as follows: section 2 describes the methods, including the model setup and experimental design; section 3 documents seasonal characteristics of sea ice area and volume as forecast in the control model with respect to reference analyses, showing the breakdown of the sea ice volume budget into component terms dependent on forecast lead time; in section 4, we then describe additional numerical simulations designed to address two distinct causes of initialization shock that are manifested in systematic errors in the control model forecast sea ice state and volume budget terms relative to analyses, briefly considering the question of whether the residual budget term tendencies in coupled NWP forecasts provide useful guidance as to the longterm state that might be reached in the same coupled model run in climate mode; section 5 concludes by discussing our main findings and their broader relevance.

\section{Methods: Models and experiments}

\section{a. Coupled model}

We use the GC2 model (Williams et al. 2015) for various coupled experiments, running at N216L85 atmosphere resolution (approximately a $60 \mathrm{~km}$ grid length in midlatitudes) and ORCA025L75 ocean resolution (a tripolar horizontal grid with resolution varying between about 10 and $20 \mathrm{~km}$ in polar latitudes). GC2 consists of component model scientific configurations GA6.0 (atmosphere), GL6.0 (land), GO5.0 (ocean), and GSI6.0 (sea ice). Details of the scientific configurations of the atmosphere and land components are given by Walters et al. (2017), of the ocean component by Megann et al. (2014) and of the sea ice component by Rae et al. (2015). The sea ice component is based on the CICE v4.1 release of the Los Alamos National Laboratory sea ice model (Hunke and Lipscomb 2010). Coupling between the atmosphere/land and ocean/sea ice components is performed using the OASIS3 coupler (Valcke 2013).

\section{b. Experimental design and model initialization}

We present results from three coupled NWP experiments: a control experiment that mimics the "NWP" configuration 
TABLE 1. Summary of the coupled experiments analyzed in this study. Note that a small number of the start dates in GC2-CTL, GC2-SDF, and GC2-DRG are missing as the hindcasts failed to run successfully for the full 15-day period.

\begin{tabular}{ll}
\hline \hline Short name & Description \\
\hline GC2-CTL & $\begin{array}{r}\text { GC2 standard coupled NWP model configuration, with hourly atmosphere-ocean coupling. Run for an annual cycle of } \\
\text { daily 15-day hindcasts for start dates between 17 Aug 2011 and 16 Sep 2012. }\end{array}$ \\
GC2-SDF & $\begin{array}{r}\text { As in GC2-CTL, but with a salinity-dependent freezing point of seawater (matching the FOAMv13 system used to } \\
\text { produce the ocean/ice analysis) rather than a fixed freezing temperature of }-1.8^{\circ} \mathrm{C} \text {. }\end{array}$ \\
GC2-DRG & $\begin{array}{c}\text { As in GC2-SDF, but with revised air-ice drag formulation more closely matching the FOAMv13 system used to produce } \\
\text { the ocean-ice analysis. }\end{array}$ \\
GC2-CLIM & $\begin{array}{l}\text { GC2 standard climate model present day control configuration, with 3-hourly atmosphere-ocean coupling. Run } \\
\text { for }>30 \text { years with greenhouse gas concentrations, aerosols, and other seasonally varying forcings set to values } \\
\end{array}$ \\
& representative of the year 2000.
\end{tabular}

described in Williams et al. (2015), hereinafter referred to as GC2-CTL, and two perturbed experiments (GC2-SDF and GC2-DRG) based on the GC2-CTL configuration. The scientific rationale and formulation differences between them are elaborated in more detail in sections 3 and 4 . We also draw some comparisons of results between the coupled NWP experiments and a coupled climate experiment (GC2CLIM) that mimics the "CLIM" configuration described in Williams et al. (2015). Table 1 summarizes the setup of the four experiments.

The experimental setup for GC2-CTL, GC2-SDF, and GC2DRG is similar to that described by Shelly et al. (2014) but here using the updated coupled model version (GC2) and covering a different study period. Our experimental setup also bears some similarities to that of Lea et al. (2015), who employed weakly coupled data assimilation run with the native coupled model to obtain analyses suitable for initializing the model components in a self-consistent way, but in our case we instead use pre-existing "analyses of opportunity" from uncoupled data assimilation systems for the initialization.

Here, we ran initialized coupled NWP hindcasts for all start dates between 17 August 2011 and 16 September 2012, i.e., covering slightly more than a complete annual cycle, all initialized at 0000 UTC and run for a 15-day forecast. The hindcasts consist of a single deterministic member for each start date, such that successive hindcasts overlap-in the manner of a time-lagged ensemble with a 1-day separation in time. For technical reasons, a small number of cases with start dates in Northern Hemisphere summer of 2012 failed to run successfully for the full 15 days; these dates are treated as missing data in our analysis.

Ocean and sea ice components of the coupled NWP model are initialized with analyses taken from the Forecast Ocean Assimilation Model (FOAM) ocean-sea ice analysis and forecasting system (Blockley et al. 2014). FOAM assimilates satellite and in situ observations of temperature, salinity, sea level anomaly, and sea ice concentration. The FOAM system used in this study was FOAMv13, a configuration using the GO5 ocean and GSI6 sea ice components at the same ORCA025 horizontal resolution as in the coupled model but incorporating a different formulation of surface exchange (consistent with FOAMv13 not being interactively coupled to the atmosphere) and of the freezing point of seawater (see section $4 \mathrm{a}$ ). For the period of study, the FOAMv13 system was forced with fluxes from the Met Office operational global NWP system as it stood at the corresponding point in time, which was then (in 2011-12) based on the older GA3.1 and GL3.1 versions of the atmosphere and land model (Walters et al. 2011). The global NWP system that forced FOAMv13 had higher resolution than GC2, tending to provide more energetic forcing of the ocean and sea ice than in the coupled model.

Atmosphere and land components of the coupled model are initialized with analyses taken from the Met Office global operational NWP system, interpolated to the N216 (horizontal) and L85 (vertical) target grids of the coupled model. As described in the previous paragraph, the operational NWP system in 2011-12 was based on the GA3.1 and GL3.1 atmosphere and land models, which means it used earlier versions of the atmosphere-land physics than in the coupled model hindcasts.

We recognize that in choosing this specific 1-yr period for the coupled NWP experiments we do not sample interannual variability. Arctic sea ice extent reached a record minimum of 3.4 million $\mathrm{km}^{2}$ in mid-September 2012 (Parkinson and Comiso 2013) so the analysis state and hence initial conditions for the coupled model forecasts toward the end of the study period could be regarded as climatologically atypical. We do not think this factor significantly affects our results or conclusions, however.

\section{c. Verification and diagnostics}

As GC2-CLIM is a free-running control climate simulation, we do not interpret its results to represent any specific individual year, so forecast verification applies only to the coupled NWP experiments.

Using coupled forecast experiments initialized from realistic states offers the potential to unravel model biases on short time scales, but availability of daily or subdaily data for verification of relevant forecast variables is a limiting factor, particularly for ocean or sea ice variables. Sea ice being the focus of this study, we therefore use analyses based on data assimilation systems instead as a basis for verification. Our aim is to characterize model biases (in the sea ice state, forcing fluxes and volume budget terms) using diagnostics that compare hindcasts against corresponding analyses. This approach is justified by the fact that the FOAM system, through its assimilation of observational sea ice concentration data from OSI-SAF (2017), provides a good estimate of sea ice cover, as demonstrated by Blockley et al. (2014; Fig. 4). 
TABLE 2. Drivers of, and interactions between, the component terms of the CICE combined sea ice and snow volume budget. The short names given in parentheses, and used elsewhere in the text, are the names of the corresponding CICE model diagnostics. All terms are positive-definite, except for evap_ai. See Hunke and Lipscomb (2010) for further details.

\begin{tabular}{|c|c|}
\hline Terms & Physics and interactions \\
\hline Basal ice growth (congel) & $\begin{array}{l}\text { Growth caused by freezing of the ocean at the base of the sea ice. Driven by surface heat loss due to a } \\
\text { cold atmosphere. Congelation growth rate will tend to be larger for thinner-than-normal sea ice. }\end{array}$ \\
\hline Frazil ice formation (frazil) & $\begin{array}{l}\text { Formation of sea ice from supercooled water in the ocean. Occurs over open ocean and sea ice leads } \\
\text { due to the atmosphere cooling the ocean surface layers, thereby causing ice crystals to form. Storms } \\
\text { can cause leads to form by divergence of the ice pack even in winter and the resultant rapid cooling } \\
\text { of the exposed ocean can generate large frazil ice formation rates. }\end{array}$ \\
\hline Surface ice melt (meltt) & $\begin{array}{l}\text { Melting at the ice surface caused by conductive or radiative heat transfer. Occurs when the sea ice } \\
\text { surface is at melting point, which can happen in winter due to warm-air intrusions but is more } \\
\text { common in summer when it is the dominant mechanism for ice melt. }\end{array}$ \\
\hline Basal ice melt (meltb) & $\begin{array}{l}\text { Melting at the base of the sea ice. Occurs when the ocean temperature rises above the } \\
\text { freezing/melting point either from advection of warm water or directly from summer heat uptake } \\
\text { in the leads from incoming radiation. The faster the ice moves relative to the ocean, the more } \\
\text { efficient will be the heat transfer to the ice due to microturbulence, increasing meltb. }\end{array}$ \\
\hline Lateral ice melt (meltl) & $\begin{array}{l}\text { Melting at the sea ice floe edges. Occurs when the ice melts from the sides solely due to a warm ocean. } \\
\text { The diameter of ice floes is assumed fixed in the model so there is no feedback from this term. }\end{array}$ \\
\hline Snowmelt (melts) & $\begin{array}{l}\text { Melting of the snow layer on top of the sea ice owing to conductive or radiative heat transfer. } \\
\text { Snowmelt must occur prior to any ice surface melting (meltt) but snow has a higher albedo than } \\
\text { solid ice so is more resistant to direct radiative melting. }\end{array}$ \\
\hline $\begin{array}{l}\text { Evaporative water flux over sea ice } \\
\text { (evap_ai) }\end{array}$ & $\begin{array}{l}\text { Increase or decrease in sea ice volume caused by evaporative water fluxes. Determined by the } \\
\text { atmospheric humidity; includes sublimation and direct condensation. }\end{array}$ \\
\hline Snowfall over sea ice (snow_ai) & $\begin{array}{l}\text { Increase in snow volume owing to snowfall. The more snow that accumulates in winter, the longer the } \\
\text { delay in general before ice surface melt will occur. Snow remaining after summer, augmented by } \\
\text { further accumulation of snow during autumn, insulates the underlying ice from the atmosphere, } \\
\text { thereby reducing the subsequent winter growth by congel. }\end{array}$ \\
\hline
\end{tabular}

Having run a complete annual cycle allows us to assess monthly mean biases (with respect to analyses) as a function of both lead time and season, with reasonable signal-to-noise given that each monthly mean is based on about 30 separate model hindcasts. The annual cycle experimental setup also provides a good baseline for testing model science changes in sensitivity experiments.

Variables examined in the analysis are confined to sea ice state variables - ice concentration, ice depth, and snow depth being the main ones-along with components of the combined sea ice and snow volume budget. For the freely running coupled model a good closure of the sea ice and snow volume budget can be achieved by integrating eight terms reported by the CICE model (Table 2). Processes involved in modeling these terms in CICE are described in more detail by Hunke and Lipscomb (2010).

An important limiting factor to bear in mind in our analysis is that sea ice concentration is the only prognostic variable assimilated in the FOAM system that produces the verifying sea ice analyses. We evaluate variables other than sea ice concentration with respect to analyses but recognize that these are only constrained indirectly by the data assimilation.

\section{Sea ice state and differences in GC2-CTL relative to FOAM analysis}

In this section we make comparisons between the forecast sea ice state in the GC2-CTL experiment and FOAMv13 reanalysis from which the initial states for those coupled hindcasts were taken. We examine time series throughout each forecast of daily means averaged over the complete Arctic and Antarctic polar region and also consider daily averages or model-minus-analysis differences for specific forecast lead times (e.g., day 5). In the latter case, rather than examining individual forecasts we compare monthly averages of the forecasts at given lead times with the corresponding mean of the analysis to reduce weather-related sampling noise. We emphasize that our analysis method does not employ averaging over the time-lagged ensemble dimension of the experiments, only over the verification time dimension for a specific month and forecast lead time.

\section{a. Arctic and Antarctic sea ice area and volume}

A comparison of total sea ice area and volume integrated over the Arctic and Antarctic regions between the daily GC2-CTL coupled model hindcasts and FOAMv13 analyses is shown in Figs. 1 and 2, respectively. It is apparent that systematic errors occur in the hindcasts relative to the analyses, more noticeably for sea ice total area, and that the differences (in either direction) mostly tend to grow with forecast lead time. The coupled model typically overestimates Arctic sea ice area throughout most of the winter season but underestimates it in summer. A similar pattern is apparent for Antarctic sea ice area but here the hindcasts tend to reverse their initial trend such that errors relative to the analysis do not grow monotonically in time. Furthermore, there is a clear separation between the analyses and coupled forecasts (at day 1) 

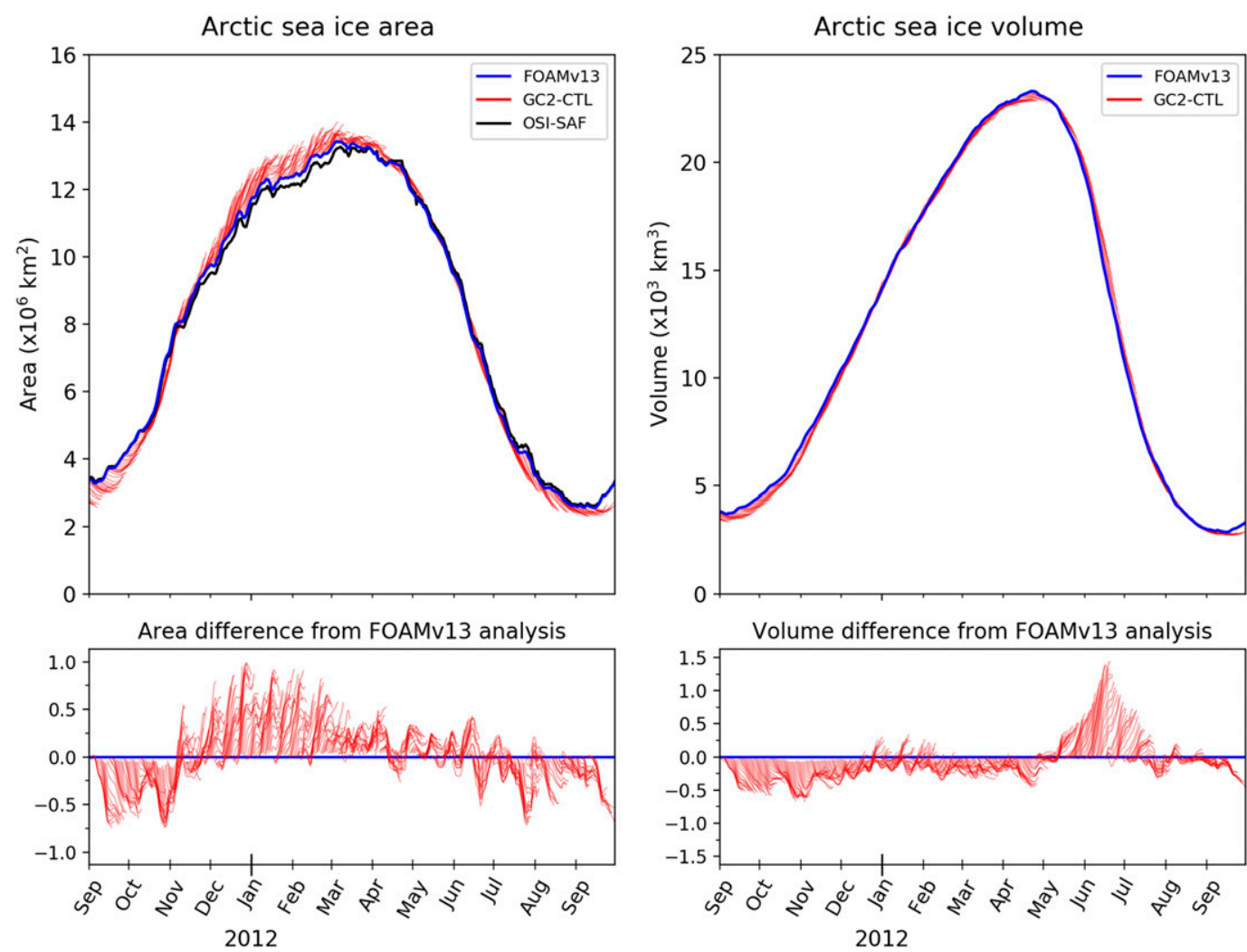

FIG. 1. Aggregated, daily mean, Arctic (left) sea ice area and (right) sea ice volume in the 15-day hindcasts performed daily with the GC2-CTL coupled model (red lines) compared to the FOAMv13 analyses (continuous blue line) from which they were initialized. (top) The actual values, illustrating the seasonal cycle, and (bottom) differences from the FOAMv13 analysis at corresponding dates. For reference, Arctic sea ice area derived from OSI-SAF observations (OSI-SAF 2017) is shown in the top-left panel. (The Arctic domain is defined here to be the whole Northern Hemisphere).

throughout much of the year for the Antarctic, suggesting a rapid adjustment away from the initial conditions-i.e., initialization shock. The Arctic tendencies show that the GC2 control model wants to grow more extensive ice in winter and melt more in summer, thus enhancing the amplitude of the seasonal cycle in ice area. The same tendency has been found in FOAMv13 model forecasts (Blockley et al. 2014), but this tendency is countered by assimilation increments in the FOAMv13 reanalysis from which we initialize the coupled model. This behavior suggests that ice formation processes such as frazil production are overly strong in winter while ice melt processes are overly strong in summer in both the coupled model and the uncoupled FOAMv13 model. The Antarctic results suggest that the annual cycle is phase shifted in the coupled model compared to the FOAMv13 reanalysis, toward a delayed summer melt and early freeze-up. Antarctic sea ice thermodynamics is driven primarily by ocean temperature changes, with a mixed layer warming in spring through the ice-albedo effect (Ohshima and Nihashi 2005) and freeze-up in autumn delayed through southward Ekman transport of warm waters (Eayrs et al. 2019), the ultimate drivers for the thermodynamic changes being atmospheric winds and sea ice dynamics (Eayrs et al. 2020).
We investigate these characteristics further in terms of seasonal volume budgets terms in section $3 b$.

For sea ice volume the deviations from the reanalysis are relatively small by comparison with sea ice area. Ice volume is largest in the ice pack interior and the coldest regions of the Arctic, and these regions therefore dominate the integrated volume in Figs. 1 and 2. As the ice is thinner toward the fringes, the changes in ice area there have a minor impact on the integrated volume. Thus, the overall integrated ice volume change is dampened relative to the integrated ice area change.

\section{b. Seasonal variations in the sea ice volume budget}

As a framework for explaining the deviations of the coupled forecasts from reanalyses at short lead time, we next present a seasonally dependent comparison of the combined sea ice and snow volume budget terms (Table 2) as diagnosed (as daily averages) for the reanalysis and at day 1 and day 10 in the coupled model hindcasts. The picture for the Arctic is shown in Fig. 3 and for the Antarctic in Fig. 4.

An important caveat in interpreting Figs. 3 and 4 is that the process of data assimilation produces increments to sea ice concentration in the analysis, with consequential increments 

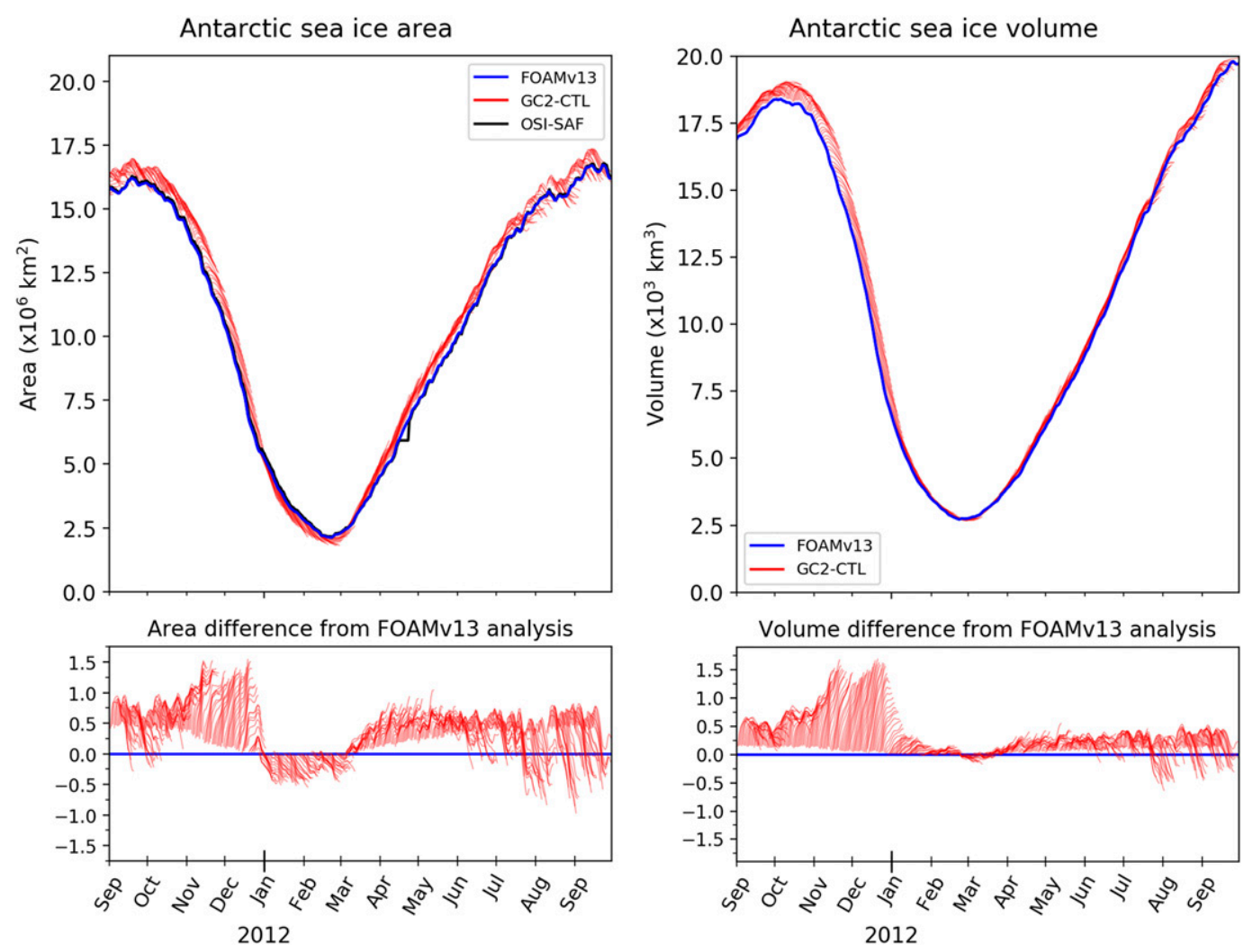

FIG. 2. As in Fig. 1, but for Antarctic sea ice area and volume. (The Antarctic domain is defined here to be the whole Southern Hemisphere).

to ice volume and the snow lying on sea ice. These analysis increments are additional terms that should be accounted for in order to close the ice volume budget for the FOAMv13 analysis. We return to this point in later discussion but neglect these increments and simply examine the diagnostics from the FOAMv13 model in analysis mode as is relative to the free-running coupled model.

The sea ice seasonal cycle is characterized by net growth through the winter and net melting during the summer. In the Arctic, summer melting is fairly evenly split between surface melting (both snow and ice), largely due to the surrounding warm landmasses, and melting at the base of the ice by the ocean, which largely occurs at lower latitudes. Meanwhile winter growth is dominated by freezing at the base of existing ice. In contrast, the sea ice around Antarctica experiences cold winds from the ice sheet and hence surface melt is relatively less important, the budget instead being controlled by the ocean through growth and melt at the base of the ice.

With reference to FOAMv13 budget terms in Fig. 3, in the Arctic in winter (mid-September to mid-April) the primary balance is between basal and frazil ice growth (congel, frazil), which is partially offset by basal melting of the ice at lower latitudes (meltb). In the summer (mid-April to mid-September) melting processes predominate; basal melting (meltb) is the dominant process with ice surface melt (meltt) in June and July_and to a lesser degree snowmelt (melts) in June-also being important contributors.

With reference to FOAMv13 budget terms in Fig. 4, in the Antarctic basal growth (congel) followed by frazil growth, as in the Arctic, are still the dominant terms during most of the winter (April-July). However, the addition of snow plays a more important role here as snowfall is more abundant in the Antarctic due to evaporation from the relatively warm circumpolar ocean releasing its moisture upon reaching the cold air mass over the sea ice, resulting in snow persisting on the ice throughout the year. In summer (September-March) the budget is heavily dominated by basal melting (meltb). Surface ice melting (meltt) is much less important in the Antarctic than in the Arctic due to the persistent snow layer, and is comparable to snow melting (melts).

It is worth noting that we are looking at the total budget of the sea ice and snow system. Transfer of snow to ice through snow depressing the ice freeboard below sea level, so forming new ice (snow-ice or white-ice), although a process within the model is not included in the budget diagnostics. This likely explains the apparent discrepancy between Arctic and Antarctic whereby Antarctic snowfall (snow_ai) is much more noticeable as a source of volume increase but snowmelt (melts) is not much different than in the Arctic.

The Arctic ice, over the first day of the coupled GC2 forecast, displays increased basal melting, less congelation growth and less frazil growth compared with FOAMv13 (Fig. 3). The top melting and snow melting, however, are very similar. This is suggestive of the coupled model either having a warmer sea surface temperature (SST) or a lower ocean freezing (or ice melting) temperature than in FOAMv13. The Antarctic frazil 

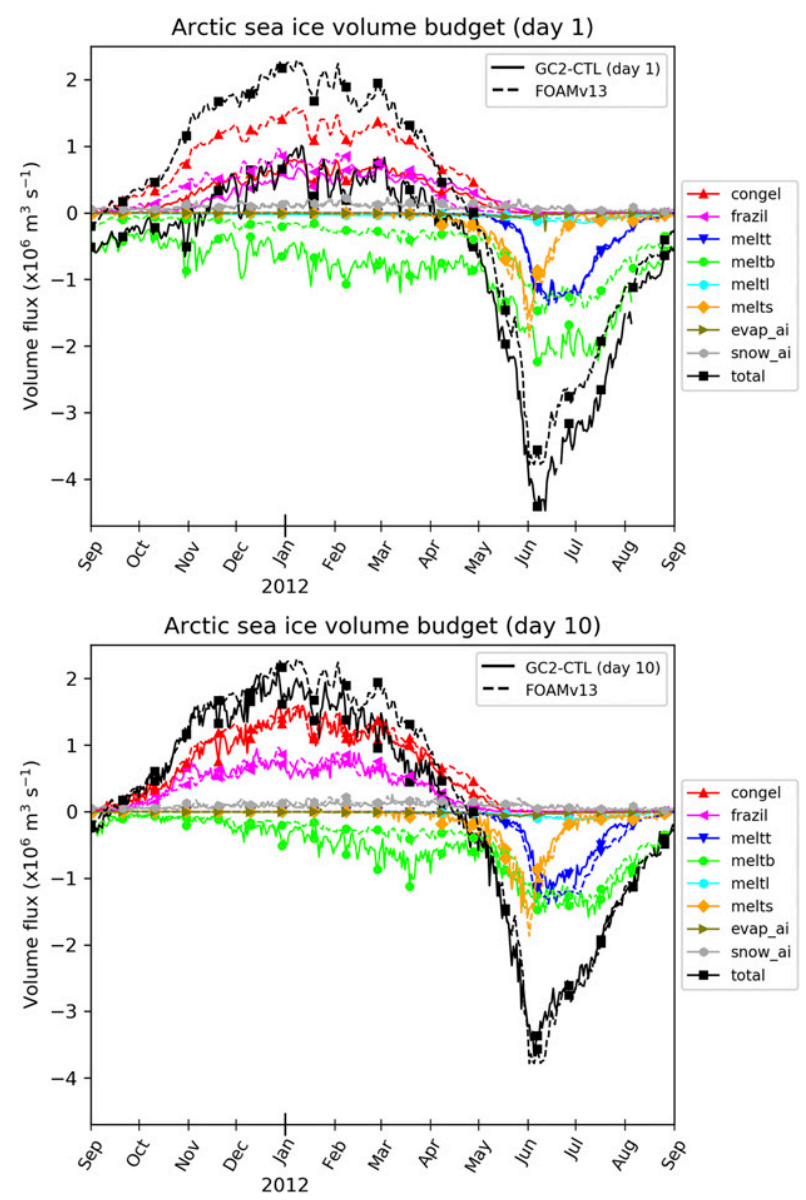

FIG. 3. Comparing GC2-CTL (solid lines) and FOAMv13 (broken lines) Arctic sea ice volume budget terms for forecast days (top) 1 and (bottom) 10.

ice growth in winter is considerably larger in the coupled GC2 model than FOAMv13 (Fig. 4), suggesting that the SST is colder or the ocean salinity freezing temperature is higher.

There is considerable spinup between day 1 and day 10 both for the Arctic and Antarctic. Differences between the coupled model and FOAMv13 for the dominant terms in the budget are generally much larger at day 1 than at day 10 . The fact that these main biases steadily reduce with forecast lead time through the intermediate forecast range from day 1 to day 10 (not shown) is a clear signature of initialization shock. The initialization shock can be thought of as the effect of an instantaneous analysis-to-forecast transition at the start of the forecast. For simplicity of presentation we choose to regard forecast day 1 as representative of the initial shock and day 10 of the more balanced situation after the effects of the initial shock have subsided.

\section{Mitigation of coupled initialization shock}

a. Initialization shock due to salinity-independent freezing

In the GC2 standard coupled NWP setup, the initialization shock apparent in Figs. 3 and 4 can largely be explained by the fact that the FOAMv13 system uses a salinity-dependent freezing temperature for seawater, whereas GC2 uses a salinity-independent formulation (i.e., fixed freezing temperature of $-1.8^{\circ} \mathrm{C}$ whatever the ocean salinity). This discrepancy leads to inconsistency in the ocean/sea ice state when initializing GC2 forecasts from FOAMv13 analyses, which is resolved by the coupled model adjusting rapidly (including near-surface ocean cooling-not shown) until it finds a more balanced state.

The coupled control experiment (GC2-CTL) was therefore repeated as a sensitivity experiment (GC2-SDF), modified so as to use the same salinity-dependent freezing temperature formulation as in FOAMv13. The initial states in GC2-SDF are more self-consistent with the coupled model forecast physics, greatly reducing the initialization shock relative to GC2-CTL. Implementation of salinity dependent freezing essentially decreases the freezing/melting temperature in the Arctic and increases it in the Antarctic because the static freezing temperature of $-1.8^{\circ} \mathrm{C}$ corresponds to an ocean salinity of approximately $33 \mathrm{ppt}$, which is more than the annual mean salinity in the Arctic but less than the mean salinity in the Antarctic (not shown).
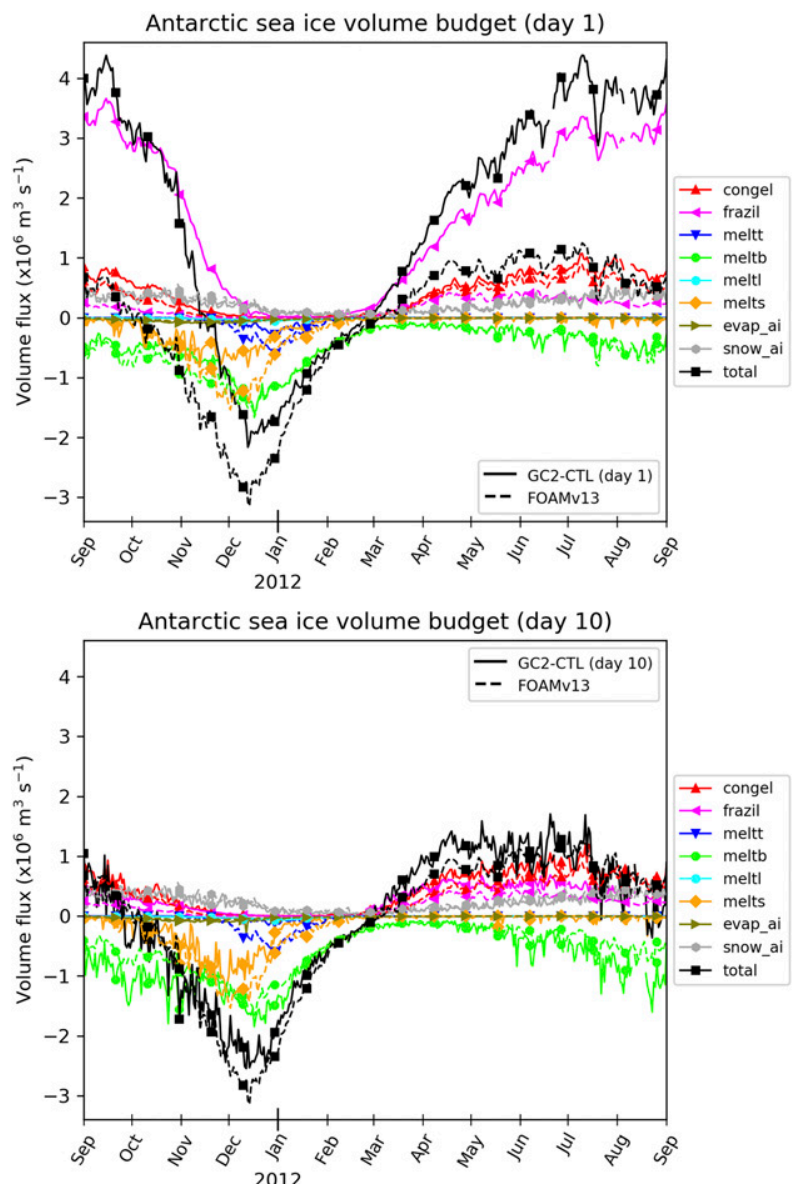

FIG. 4. Comparing GC2-CTL (solid lines) and FOAMv13 (broken lines) Antarctic sea ice volume budget terms for forecast days (top) 1 and (bottom) 10 . 

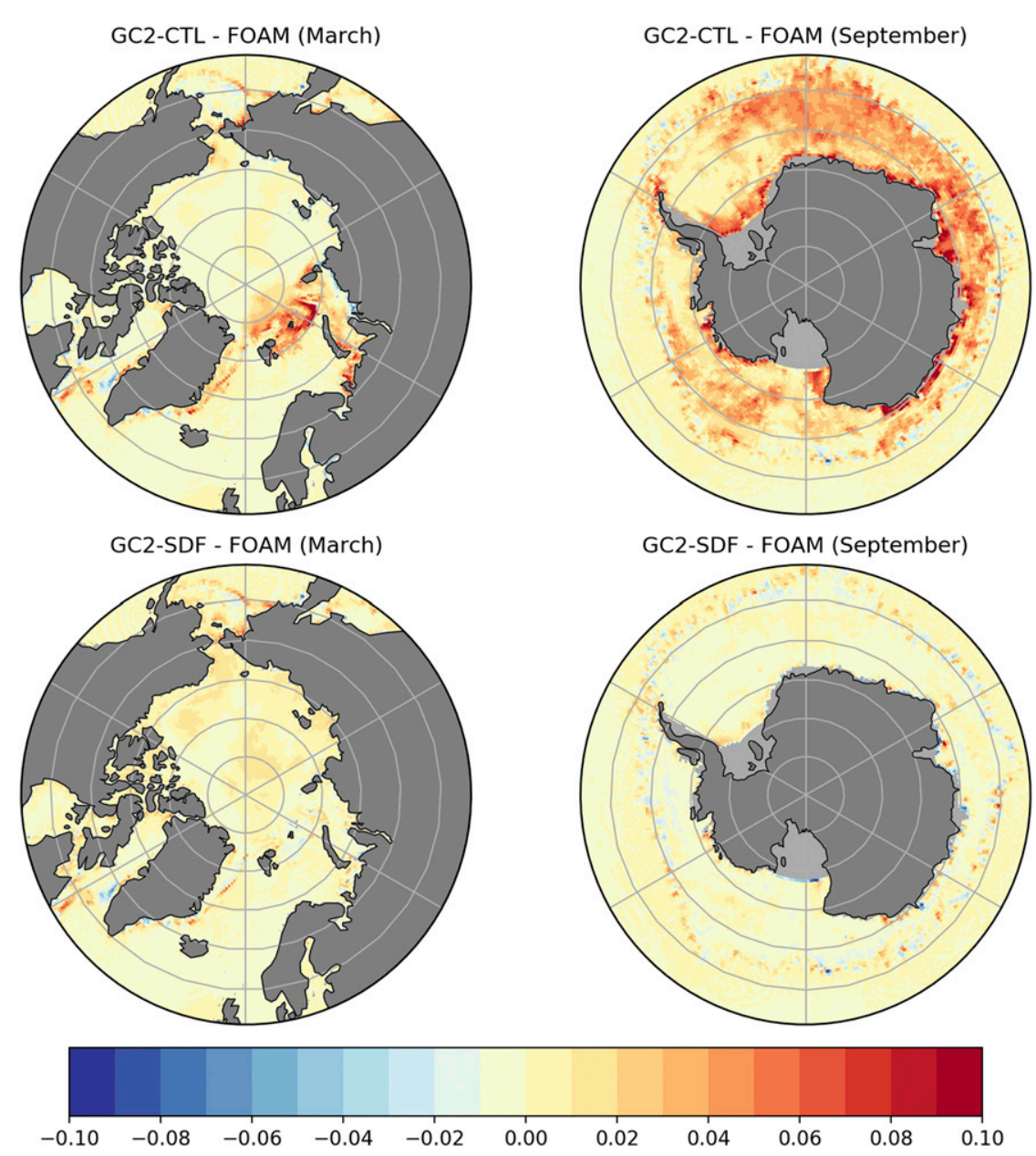

FIG. 5. Monthly mean ice concentration differences from FOAMv13 analyses for forecast day 1 in the (top) GC2-CTL and (bottom) GC2-SDF experiments for (left) the Arctic in March 2012 and (right) the Antarctic in September 2011.

We illustrate the improvement arising from this change in Fig. 5, which shows a greatly reduced day 1 spatial bias in the sea ice concentration fields in both the Arctic and Antarctic. The improvement in mean bias at short range is reflected in a much closer agreement between the analysis and GC2-SDF forecasts for integrated sea ice area at day 1 (not shown).

Furthermore, differences between GC2-SDF day 1 forecasts and FOAMv13 reanalyses for the individual sea ice volume budget terms are markedly reduced overall (Fig. 6, top panel, showing the Antarctic only) when compared with GC2-CTL (Fig. 4, top panel). The extra Antarctic frazil ice formation in open water evident in GC2-CTL is not present for GC2-SDF. Likewise, in the Arctic, basal growth is higher and basal melt lower for GC2-SDF, improving agreement with FOAMv13.

In the Antarctic, exceptions to the general improvement in day 1 budget terms compared to FOAM are for meltb and melts. In GC2-SDF meltb is now well above FOAMv13 in magnitude for about two-thirds of the year (i.e., increased melting), while melts continues to exhibit sizeable differences from FOAMv13 in Antarctic winter (November to January). The error characteristics for meltb and melts remain much more similar between day 1 and day 10 than is the case for the other terms (Fig. 6). Day 10 Antarctic volume budget terms in GC2-SDF (Fig. 6, bottom panel) mostly maintain similar characteristics to GC2-CTL (Fig. 4, bottom panel). Remaining differences are likely related to the atmospheric forcing from the NWP model used to drive FOAMv13 and the preferred state of $\mathrm{GC} 2$, as regards the energetics of the systems.

A plausible explanation for the systematic differences in melts in GC2-CTL and GC2-SDF relative to FOAMv13 (Figs. 4 and 6) is that the atmospheric forcing in the NWP model used to drive FOAMv13 does not include snow cover on sea ice, with consequences both in lowering the sea ice albedo and increasing the thermal conductivity. Near surface atmospheric temperatures therefore tend to be higher in the FOAMv13 forcing than in the coupled hindcasts. This effect is highlighted by Batrak and Müller (2019) in the context of reanalyses for the Arctic and also noted by Vellinga et al. (2020) in a separate coupled NWP study. In our case, the effect is most prominent for the 

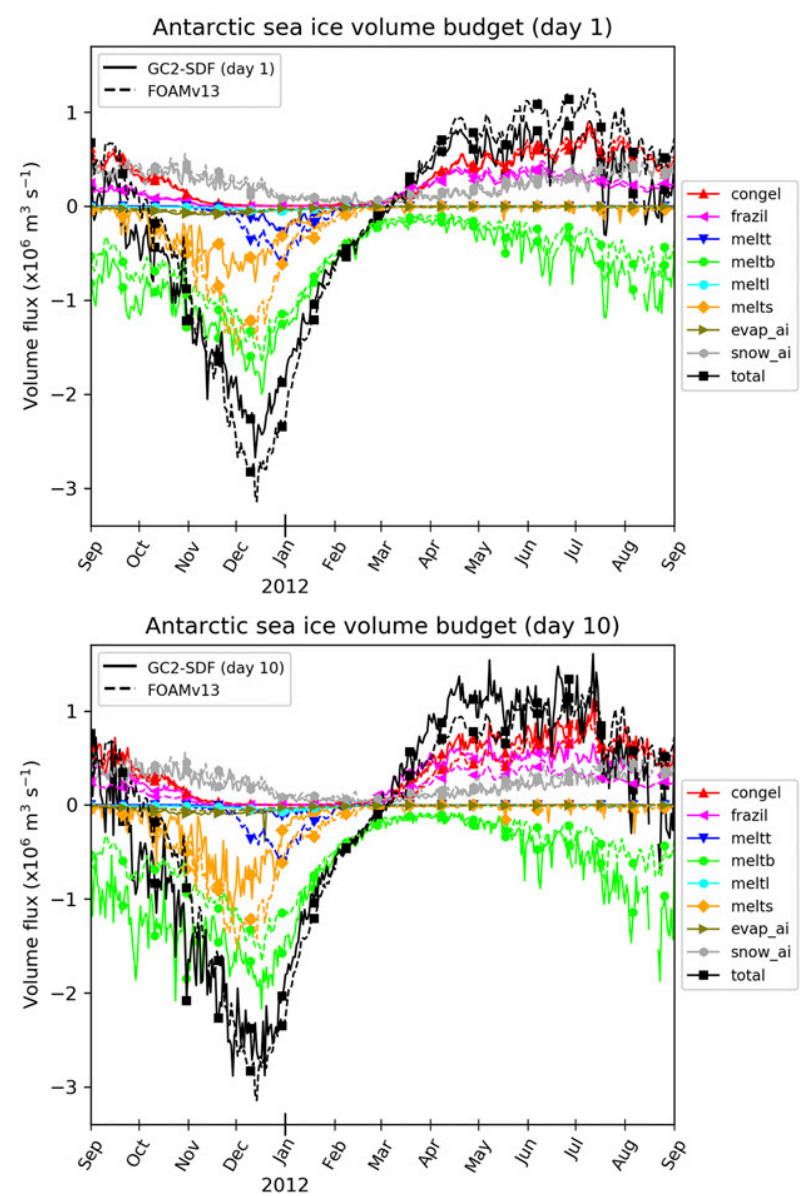

FIG. 6. Comparing GC2-SDF (solid lines) and FOAMv13 (broken lines) Antarctic sea ice volume budget terms for forecast days (top) 1 and (bottom) 10.

Antarctic (Fig. 4) where sea ice is almost always covered by snow, in contrast to the Arctic (Fig. 3) where snow cover on sea ice is less ubiquitous.

The meltb differences in GC2-CTL and GC2-SDF relative to FOAMv13 (Figs. 3, 4 and 6) can potentially also be attributed to differences in the atmospheric forcing, specifically in the wind forcing as translated to surface drag on the sea ice. Ice motion relative to the underlying ocean is a significant factor driving meltb (Table 2), basal heat transfer to the ice being parameterized through a microturbulence scheme (McPhee 1987). The effect of differences in surface drag on meltb is explored further in section $4 \mathrm{~b}$.

\section{b. Initialization shock due to atmosphere-ice drag formulation}

FOAMv13 uses the CICE standard surface exchange scheme, which assumes a fixed roughness length over sea ice (with respect to the $10 \mathrm{~m}$ reference height) in calculating the atmospheric neutral surface drag. The drag calculated by the scheme is then scaled by the sea ice fraction in the grid box to determine the total sea ice (wind) drag in that grid box. The standard CICE scheme uses a default setting for roughness length of $0.5 \mathrm{~mm}$, giving a dimensionless drag coefficient of about 1630. However, FOAMv13 uses a higher value $(3 \mathrm{~mm})$ than the default setting for roughness length, giving a drag coefficient of about 2430. The higher value in FOAMv13 is selected to match that in its driving NWP model, which used such a value to improve the short time-scale surface pressure fields of the model analysis.

By contrast, GC2-CTL uses a variable scheme in which drag is increased over the marginal ice zone (MIZ), in part to account for the missing influence of form drag associated with the ice flow edges. The peak roughness length in the MIZ is $0.1 \mathrm{~m}$, a value considerably higher than that inferred from observations (Elvidge et al. 2016). The roughness length ramps up from $0.5 \mathrm{~mm}$ for an ice fraction of 1.0 ("pack ice") to the peak value at an ice fraction of 0.7 (MIZ), then linearly ramps down to the ocean value at an ice fraction of zero. The high value of MIZ roughness was required by the atmosphere-only NWP model in order to improve sea level pressure verification. Improvements in the drag physics scheme (Renfrew et al. 2019) have recently obviated the need for roughness length to be tuned differently for each atmospheric model version to optimize its performance (as was the case here for FOAMv13's driving NWP model and the atmosphere-only NWP model related to GC2).

The picture for ice speed is complicated by the fact that the FOAMv13 analysis was forced with NWP model winds from a different atmospheric physics version, i.e., GA3.0 (Walters et al. 2011) and at a higher atmospheric resolution (N512 compared with N216 in the GC2 configuration). However, the differences in air-ice drag physical formulation between FOAMv13 and GC2 are likely mostly responsible for the ice speed differences apparent between GC2-SDF and GC2-DRG.

The initialization shock to ice speed at day 1 greatly improves in going from GC2-CTL and GC2-SDF to GC2-DRG (Fig. 7), although a small residual effect lingers around the margins of the ice pack. This is most likely a response to the atmospheric near-surface wind adjusting in GC2-DRG in response to the reduced surface drag, i.e., an acceleration of the $10 \mathrm{~m}$ wind as a reaction to the reduced surface roughness (Fig. 8).

The interplay between surface drag over sea ice and atmospheric winds means that we cannot realistically expect to eliminate initial adjustments in both atmospheric winds and ice motion at the same time, when using the initial conditions involved in these experiments. Nonetheless, as a result of more similar ice motion, the basal melt (meltb) component, and consequently total, seasonal volume budget terms are considerably closer to the FOAMv13 analysis in GC2-DRG at day 1 (Fig. 9) than is the case in GC2-SDF (Fig. 6), although systematic differences in melts remain in the Antarctic (for the reasons discussed above). This further significant reduction in the initialization shock that arises in GC2-DRG as a consequence of bringing the air-ice drag formulation more closely into line with the FOAMv13 system, as expressed in the sea ice volume budget, is consistent with the strong influence of ice drift speed relative to the ocean on the basal heat transfer to the ice (Table 2). 

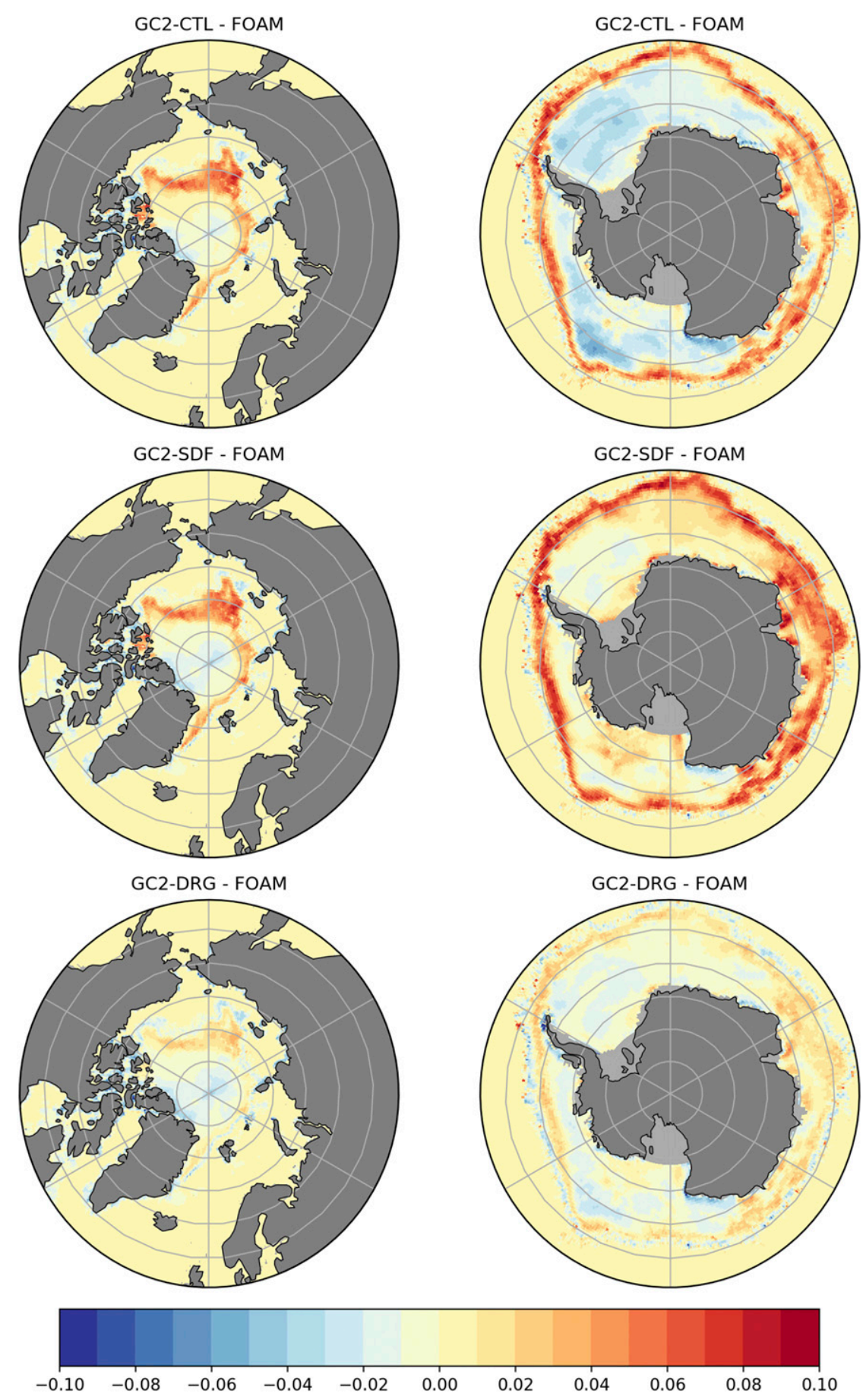

FIG. 7. September 2011 monthly mean ice speed differences from FOAMv13 analyses for forecast day 1 from (top) GC2-CTL, (middle) GC2-SDF, and (bottom) GC2-DRG.

Examination of the distributions of forecast errors relative to FOAMv13 analyses in both ice concentration and ice speed in the marginal ice zone, illustrated as monthly mean day 1 errors for September 2011 (Fig. 10), show only modest improvements in ice fractions in GC2-SDF and GC2-DRG (lower mean and standard deviation relative to GC2-CTL) but a clear improvement in forecast ice speeds in GC2-DRG (marked reduction in mean and standard deviation relative to both GC2-CTL and GC2-SDF). However, as ice speed is not directly assimilated in FOAMv13 analyses, this reduced initialization shock in GC2-DRG may represent in large part a signal of improved consistency between FOAMv13 and GC2-DRG 

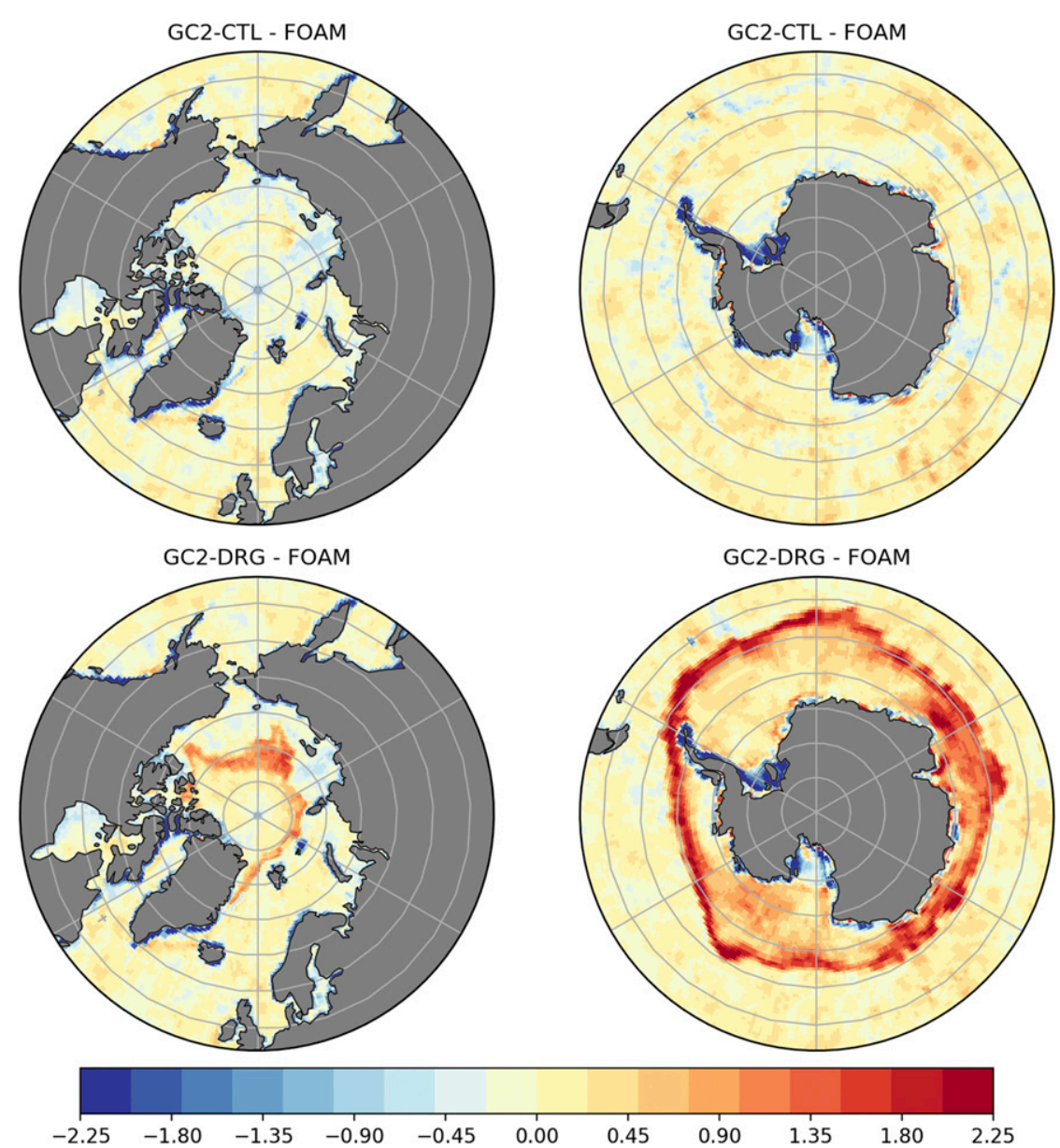

FIG. 8. September 2011 monthly mean $10 \mathrm{~m}$ wind speed differences from FOAMv13 forcing data for day 1 forecasts from (top) GC2-CTL and (bottom) GC2-DRG.

physics related to dynamical forcing of sea ice rather than an improvement in forecast skill in GC2-DRG relative to true ice speeds.

\section{c. Comparison of sea ice budget terms from NWP to climate time scales}

Having reduced the initialization shock in sea ice to a substantial degree, we last consider whether the residual tendencies in sea ice budget terms over the course of the coupled NWP forecasts give useful guidance as to the long-term state that might be reached by the same model run in climate mode. This is a question pertinent to the Met Office's strategy for seamless model development in that traceability of model errors from NWP to climate time scales potentially permits short NWP experiments to be used efficiently as a proxy for climate experiments in the model development process leading to improved versions of the coupled climate model-for use in Coupled Model Intercomparison Project (CMIP) experiments and other climate applications.

To investigate this question, we examine the seasonal cycles of selected terms in the sea ice volume budget, comparing results from the GC2-DRG experiment (NWP time scale) against fully spunup results from the GC2-CLIM experiment (climate time scale)-see Table 1. A complicating factor is that the GC2 climate model exhibits a pronounced Southern Ocean warm SST bias (Williams et al. 2015) that is primarily related to deficiencies in modeling of cloud (Hyder et al. 2018) rather than sea ice. Its impact on the sea ice volume budget terms in GC2-CLIM produces a very substantial divergence from both the FOAMv13 analysis and GC2-DRG results. This large drift on climate time scales hampers the interpretation of coupled NWP versus climate results for the Antarctic so we only discuss Arctic results here, for which the sea ice state in GC2-CLIM remains realistic.

Figure 11 shows selected Arctic sea ice volume budget terms - comparing the FOAMv13 analysis, GC2-DRG at three different forecast lead times $(1,5$, and 15 days), and 30-yr means from GC2-CLIM. We recognize that using GC2-DRG rather than the GC2-CTL experiment as the NWP time-scale comparator is not ideal in that there are minor science differences between this coupled NWP configuration and the GC2-CLIM climate configuration, but GC2-DRG is the best choice available among the coupled NWP experiments discussed here to address the question of interest as it has the 

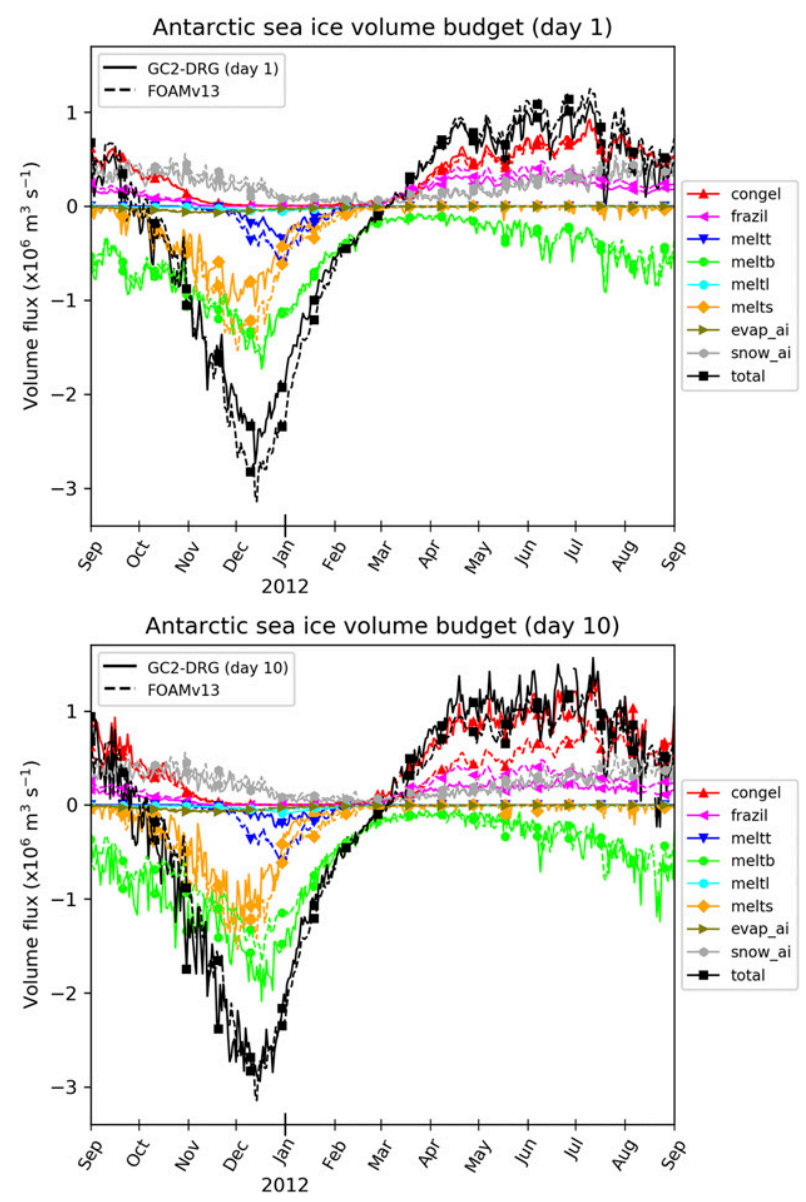

FIG. 9. Comparing GC2-DRG (solid lines) and FOAMv13 (broken lines) Antarctic sea ice volume budget terms for forecast days (top) 1 and (bottom) 10.

smallest initialization shock in sea ice. Even if the coupled model were highly realistic in terms of its mean state and internal variability, we would also expect differences to arise because (by design) FOAMv13 and GC2-DRG results represent a single specific year running from 2011to 2012 whereas GC2-CLIM results represent a 30-yr mean of the model's control state.

With the exception of frazil (which exhibits a noticeable initialization shock), there is good agreement between the FOAM analysis and day 1 for the majority of the terms in Fig. 11. The ice formation terms congel and frazil show substantial adjustments from day 1 to day 15 such that at day 15 both terms lie closer to the climate state than the analysis, despite respective overshooting and undershooting the climate state in winter (November-March). However, the four melt terms (meltb, melt, meltl and melts) do not show such strong trends toward the climate state going from day 1 to day 15 , rather remaining generally closer to the analysis than to the climate state. In summer (June-August), meltl trends toward the climate state but the rate of convergence through the forecast appears to be relatively slower than for congel and frazil in winter. From January to April, meltb also shows a slow convergence to the climate state. By contrast, in June and July both meltb and meltt tend to drift farther away from rather than toward the climate state through the forecast.

Despite the limitations associated with our experimental setup and specific model, these results indicate that a combination of coupled NWP and climate experiments offers a potentially useful insight on the traceability of model errors in sea ice volume budget terms across time scales, at least for some terms at some times of year. Experiments exploring the intermediate seasonal-to-annual forecast time scales beyond the 15-day forecast period covered here might shed further light on the slower time-scale development of the responses of the different terms and the degree of nonlinearly in their responses.

\section{Discussion}

We have attributed initialization shock in the GC2-CTL and GC2-SDF experiments primarily to discrepancies between the model physics in the GC2 coupled NWP model and the forced ocean-ice model system that generated the ocean and sea ice analyses used for the initialization. Sea ice provides a strong test for initialization shock in that it is strongly coupled both to atmospheric and oceanic processes, responds on fast time scales, and the modeled sea ice variables (apart from sea ice fraction) are only indirectly constrained by assimilated data leaving multiple internal degrees of freedom in the state of the sea ice model component.

Initialization shock was reduced in GC2-DRG by bringing the coupled NWP model formulation more closely into line with the forced model system but systematic differences remain in atmospheric forcing of the sea ice between the forced analysis system and coupled NWP model that are hard to eliminate in our existing experimental setup. The remaining issues can be attributed partly to (i) differences in the physics/ dynamics in the atmospheric model version generating the atmosphere-to-ice fluxes (GA3.0 for the FOAMv13 system vs GA6.0 in the GC2 coupled NWP model), (ii) differences in the bulk formulation used for surface fluxes, (iii) differences in the effective atmosphere model resolution (higher resolution in the forced system), (iv) technical differences in time sampling of atmosphere-to-ice fluxes as applied to the sea ice, and (v) differences related to the increments in the data assimilation. The presence of fully coupled feedbacks in the coupled model that are not captured in the FOAMv13 system is probably also a factor but we do not think this is likely to have played a significant role in the context of this study.

Narrowing the differences with the forced ocean-sea ice analysis system in an ad hoc way to mitigate inherent initialization shock is not necessarily the most practical way to improve coupled NWP model performance. A more robust, although technically demanding strategy, would be to initialize coupled NWP forecasts from analyses generated by a coupled data assimilation system run with the same (native) version of the coupled NWP model. Mulholland et al. (2015) and Guiavarc'h et al. (2019) demonstrate that such a coupled data assimilation is likely required to generate sufficiently wellbalanced initial conditions for coupled NWP purposes to avoid a degradation in forecast skill relative to an equivalent 

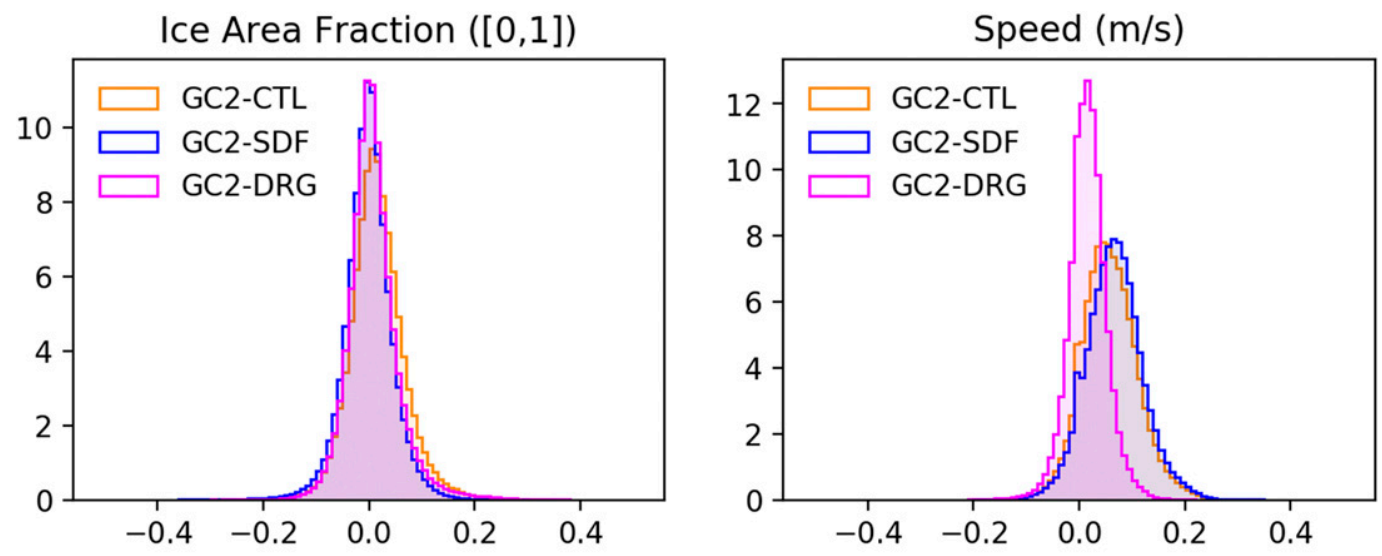

\begin{tabular}{|l|c|c|}
\cline { 2 - 3 } \multicolumn{1}{c|}{} & Mean & S.Dev \\
\hline GC2-CTL & 0.015 & 0.053 \\
\hline GC2-SDF & -0.002 & 0.047 \\
\hline GC2-DRG & 0.008 & 0.051 \\
\hline
\end{tabular}

\begin{tabular}{|l|l|l|}
\cline { 2 - 3 } \multicolumn{1}{c|}{} & Mean & S.Dev \\
\hline GC2-CTL & 0.057 & 0.054 \\
\hline GC2-SDF & 0.066 & 0.055 \\
\hline GC2-DRG & 0.015 & 0.037 \\
\hline
\end{tabular}

FIG. 10. Histograms of mean differences from FOAMv13 analyses for (left) ice concentration and (right) ice speed in September 2011 for forecast day 1 of GC2-CTL, GC2-SDF, and GC2-DRG. The sampling is restricted to grid points in the Antarctic where the daily mean ice concentration in both the GC2 experiment and FOAMv13 analysis lies in the range $[0.4,0.8]$. Means and standard deviations of each distribution are given in the inset tables below each histogram.

uncoupled global NWP model (or an uncoupled marine forecasting system in the case of ocean forecast skill). Further research is needed into the optimum coupled data assimilation techniques for coupled NWP systems, but some such methodology seems likely to be necessary to minimize the impact of the coupled initialization shocks we have investigated here for sea ice. Nonetheless, we note that useful skill in sea ice forecasts has been demonstrated in recent coupled NWP experiments with the MetUM in a high-resolution configuration in which the initialization shock issues described here are less prominent (Vellinga et al. 2020), even without using a coupled data assimilation in the initialization procedure.

In practice, coupled NWP can only be expected to supersede conventional "uncoupled" NWP for operational forecasting purposes when the forecast skill in coupled NWP mode (whether initialized using coupled data assimilation or not) consistently exceeds that of uncoupled NWP. It remains a future goal for the Met Office to transition to coupled NWP (in association with coupled data assimilation) for operational forecasting, but coupled NWP testing already plays an important role in the evaluation and selection of science changes for future model updates within its ongoing coupled model development program (Brown et al. 2012), alongside seasonal and climate model testing. Another area of scientific interest is the potential of bringing coupled NWP experiments into the scope of experimental designs such as that exemplified by the U.K. Climate Projections 2018 (UKCP18) project (Murphy et al. 2018), in which initialized NWP experiments, perturbed parameter and multimodel ensembles are combined and exploited to understand model systematic errors and their sensitivity, as part of the challenge of quantifying uncertainty in climate change projections.
Coupled NWP hindcast experiments of the type described here can potentially provide a "fast" testing framework in which to explore the evolution of coupled model biases in multiple variables, including the sea ice state and budget terms that we have illustrated here. A generic framework of this type could theoretically be applied to multiple climate models run in coupled NWP mode in a manner analogous to the Transpose-AMIP protocol (Williams et al. 2013). In Transpose-AMIP the atmosphere component of climate models is run in weather forecast mode for a small number of selected cases to evaluate and understand processes operating in the model in comparison with observations, helping to inform future model development (Williamson et al. 2005). Developing an analogous coupled NWP protocol ("Transpose-CMIP") for model intercomparison purposes would require a generalizable and effective method for coupled initialization that avoids excessive initialization shock, as well as sufficiently detailed data for validation of the ocean and sea ice components. Given our findings, the Transpose-AMIP approach of using the same atmosphere analyses to initialize all atmospheric models may not translate effectively to the requirements of initializing the ocean and sea ice component of coupled NWP models. Using nonnative analyses from a common source as a basis for initializing coupled NWP case studies would likely make them prone to significant initial error growth in some components of the coupled model due to initialization shock, as we have demonstrated here in the context of sea ice. Analysis of such errors would not necessarily provide much useful information about underlying process-based errors in coupled models in general, reducing the value of model intercomparison. Using initial conditions based on analyses from a coupled data assimilation system run with the native (or a structurally very 

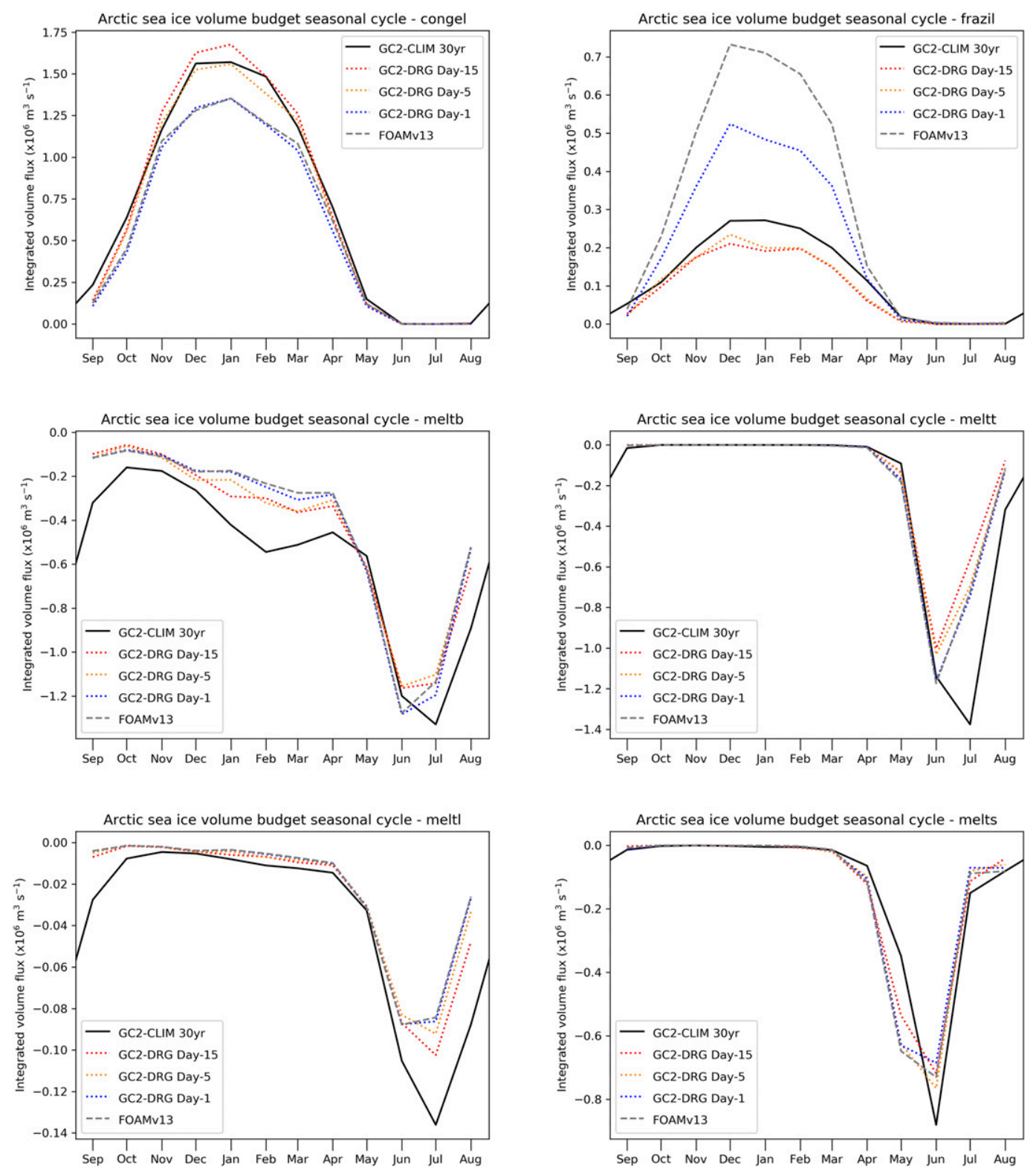

FIG. 11. Combined NWP and climate-time-scale views of the seasonal cycle of the integrated Arctic ice volume budget for a subset of terms, based on monthly means from the FOAMv13 analysis (gray dashed line), the GC2-DRG experiment at forecast day-1, day-5, and day-15 lead times (colored broken lines), and 30-yr means from the GC2-CLIM climate experiment (black solid line).

similar) coupled model should reduce undesirable impacts of initialization shock but encapsulating such a method in the protocol for coupled NWP model intercomparison appears to be difficult.

Acknowledgments. We are grateful to Dan Copsey for advice on technical details of the model configurations and for executing the GC2-CLIM experiment. This work was supported by the Met Office Hadley Centre Climate Programme funded by BEIS and Defra. We are grateful to editor Daniel Hodyss for his efficient handling or our manuscript and to three anonymous referees whose comments have helped to improve this paper.

Data availability statement. FOAM analyses are available through the Copernicus Marine Environment Monitoring Service (CMEMS; http://marine.copernicus.eu/) global ocean analysis and forecast product (ID: GLOBAL_ANALYSISFORECAST_PHY_CPL_ 001_015; described in https://resources.marine.copernicus.eu/ documents/QUID/CMEMS-GLO-QUID-001-015.pdf). The nature of the daily and subdaily data generated in running the coupled model hindcast experiments requires a large tape 
storage facility. There are currently no on-demand facilities provided by the Met Office to accommodate ad hoc data requests from the type of research experiments analyzed in this study, but anyone who is interested in accessing data from the GC2-CTL (ID: mi-ab598_cplfcst_ctl), GC2-SDF (ID: mi-ah380), GC2-DRG (ID: mi-at812), and GC2-CLIM (ID: mi-ah023) experiments should consult the authors.

\section{REFERENCES}

Batrak, Y., and M. Müller, 2019: On the warm bias in atmospheric reanalyses induced by the missing snow over Arctic sea-ice. Nat. Commun., 10, 4170, https://doi.org/10.1038/s41467-01911975-3.

Belcher, S. E., H. T. Hewitt, A. Beljaars, E. Brun, B. Fox-Kemper, J.-F. Lemieux, G. Smith, and S. Valcke, 2015: Ocean-wavessea ice-atmosphere interactions. Seamless Prediction of the Earth System: From Minutes to Months, G. Brunet, S. Jones, and P. Ruti, Eds., World Meteorological Organization, 155-169.

Blackport, R., and J. A. Screen, 2020: Weakened evidence for midlatitude impacts of Arctic warming. Nat. Climate Change, 10, 1065-1066, https://doi.org/10.1038/s41558-020-00954-y.

_ _ _ - K. van der Wiel, and R. Bintanja, 2019: Minimal influence of reduced Arctic sea ice on coincident cold winters in mid-latitudes. Nat. Climate Change, 9, 697-704, https:// doi.org/10.1038/s41558-019-0551-4.

Blockley, E., and Coauthors, 2014: Recent development of the Met Office operational ocean forecasting system: An overview and assessment of the new Global FOAM forecasts. Geosci. Model Dev., 7, 2613-2638, https://doi.org/10.5194/ gmd-7-2613-2014.

Brassington, G. B., and Coauthors, 2015: Progress and challenges in short- to medium-range coupled prediction. J. Oper. Oceanogr., 8, s239-s258, https://doi.org/10.1080/1755876X.2015.1049875.

Brown, A., S. Milton, M. Cullen, B. Golding, J. Mitchell, and A. Shelly, 2012: Unified modeling and prediction of weather and climate: A 25-year journey. Bull. Amer. Meteor. Soc., 93, 1865-1877, https://doi.org/10.1175/BAMS-D-12-00018.1.

Eayrs, C., and Coauthors, 2019: Understanding the seasonal cycle of Antarctic sea ice extent in the context of longer-term variability. Rev. Geophys., 57, 1037-1064, https://doi.org/10.1029/ 2018RG000631.

— D. Faller, and D. M. Holland, 2020: Mechanisms driving the asymmetric seasonal cycle of Antarctic sea ice in the CESM large ensemble. Ann. Glaciol., 61, 171-180, https://doi.org/ 10.1017/aog.2020.26.

Elvidge, A., I. Renfrew, A. Weiss, I. Brooks, T. Lachlan-Cope, and J. King, 2016: Observations of surface momentum exchange over the marginal ice zone and recommendations for its parametrisation. Atmos. Chem. Phys., 16, 1545-1563, https:// doi.org/10.5194/acp-16-1545-2016.

Goessling, H., and Coauthors, 2016: Paving the way for the year of polar prediction. Bull. Amer. Meteor. Soc., 97, ES85-ES88, https://doi.org/10.1175/BAMS-D-15-00270.1.

Guiavarc'h, C., J. Roberts-Jones, C. Harris, D. J. Lea, A. Ryan, and I. Ascione, 2019: Assessment of ocean analysis and forecast from an atmosphere-ocean coupled data assimilation operational system. Ocean Sci., 15, 1307-1326, https://doi.org/ 10.5194/os-15-1307-2019.

Haiden, T., M. Janousek, J. Bidlot, L. Ferranti, F. Prates, F. Vitart, P. Bauer, and D. S. Richardson, 2017: Evaluation of ECMWF forecasts, including 2016-2017 upgrades. ECMWF Tech. Memo. 817, 56 pp., https://doi.org/10.21957/x397za5p5.
Handorf, D., R. Jaiser, K. Dethloff, A. Rinke, and J. Cohen, 2015: Impacts of Arctic sea ice and continental snow cover changes on atmospheric winter teleconnections. Geophys. Res. Lett., 42, 2367-2377, https://doi.org/10.1002/2015GL063203.

$\mathrm{Hu}$, C., and Coauthors, 2016: Shifting El Niño inhibits summer Arctic warming and Arctic sea-ice melting over the Canada basin. Nat. Commun., 7, 11721, https://doi.org/10.1038/ncomms11721.

Hunke, E. C., and W. H. Lipscomb, 2010: CICE: The Los Alamos Sea Ice Model documentation and software user's manual, version 4.1. Tech. Doc. LA-CC-06-012, 76 pp.

Hyder, P., and Coauthors, 2018: Critical Southern Ocean climate model biases traced to atmospheric model cloud errors. Nat. Commun., 9, 3625, https://doi.org/10.1038/s41467-01805634-2.

Jung, T., M. A. Kasper, T. Semmler, and S. Serrar, 2014: Arctic influence on subseasonal midlatitude prediction. Geophys. Res. Lett., 41, 3676-3680, https://doi.org/10.1002/2014GL059961.

_- and Coauthors, 2016: Advancing polar prediction capabilities on daily to seasonal time scales. Bull. Amer. Meteor. Soc., 97, 1631-1647, https://doi.org/10.1175/BAMS-D-14-00246.1.

Lea, D., I. Mirouze, M. Martin, R. King, A. Hines, D. Walters, and M. Thurlow, 2015: Assessing a new coupled data assimilation system based on the Met Office coupled atmosphere-landocean-sea ice model. Mon. Wea. Rev., 143, 4678-4694, https:// doi.org/10.1175/MWR-D-15-0174.1.

McPhee, M. G., 1987: A time-dependent model for turbulent transfer in a stratified oceanic boundary layer. J. Geophys. Res., 92, 6977-6986, https://doi.org/10.1029/JC092iC07p06977.

Megann, A. P., and Coauthors, 2014: GO 5.0: The joint NERC-Met Office NEMO global ocean model for use in coupled and forced applications. Geosci. Model Dev., 7, 1069-1092, https:// doi.org/10.5194/gmd-7-1069-2014.

Mulholland, D., P. Laloyaux, K. Haines, and M. Balmaseda, 2015: Origin and impact of initialization shocks in coupled atmosphereocean forecasts. Mon. Wea. Rev., 143, 4631-4644, https://doi.org/ 10.1175/MWR-D-15-0076.1.

Murphy, J. M., and Coauthors, 2018: UKCP18 Land Projections: Science Report. Accessed 2 June 2021, https:/ukclimateprojections. metoffice.gov.uk.

Ohshima, K. I., and S. Nihashi, 2005: A simplified ice ocean coupled model for the Antarctic ice melt season. J. Phys. Oceanogr., 35, 188-201, https://doi.org/10.1175/JPO-2675.1.

OSI-SAF, 2017: OSI SAF EUMETSAT Ocean and Sea Ice Satellite Application Facility, Global sea ice concentration climate data record 1979-2015 (v2.0). Norwegian and Danish Meteorological Institutes, accessed 2 June 2021, https://doi.org/10.15770/EUM_ SAF_OSI_0008.

Overland, J., 2016: A difficult Arctic science issue: Midlatitude weather linkages. Polar Sci., 10, 210-216, https://doi.org/ 10.1016/j.polar.2016.04.011.

Parkinson, C., and J. Comiso, 2013: On the 2012 record low Arctic sea ice cover: Combined impact of preconditioning and an August storm. Geophys. Res. Lett., 40, 1356-1361, https:// doi.org/10.1002/grl.50349.

Pellerin, P., H. Ritchie, F. Saucier, F. Roy, S. Desjardins, M. Valin, and V. Lee, 2004: Impact of a two-way coupling between an atmospheric and an ocean-ice model over the Gulf of St. Lawrence. Mon. Wea. Rev., 132, 1379-1398, https://doi.org/ 10.1175/1520-0493(2004)132<1379:IOATCB > 2.0.CO;2.

Rae, J. G. L., and Coauthors, 2015: Development of the global sea ice 6.0 CICE configuration for the Met Office global coupled model. Geosci. Model Dev., 8, 2221-2230, https://doi.org/ 10.5194/gmd-8-2221-2015. 
Renfrew, I. A., A. D. Elvidge, and J. Edwards, 2019: Atmospheric sensitivity to marginal-ice-zone drag: Local and global responses. Quart. J. Roy. Meteor. Soc., 145, 1165-1179, https:// doi.org/10.1002/qj.3486.

Shelly, A., P. Xavier, D. Copsey, T. Johns, J. M. Rodríguez, S. Milton, and N. Klingaman, 2014: Coupled versus uncoupled hindcast simulations of the Madden-Julian Oscillation in the year of tropical convection. Geophys. Res. Lett., 41, 5670-5677, https://doi.org/10.1002/2013GL059062.

Smith, G. C., F. Roy, and B. Brasnett, 2013: Evaluation of an operational ice-ocean analysis and forecasting system for the Gulf of St Lawrence. Quart. J. Roy. Meteor. Soc., 139, 419-433, https://doi.org/10.1002/qj.1982.

— ocean model on global medium-range NWP forecast skill. Mon. Wea. Rev., 146, 1157-1180, https://doi.org/10.1175/MWRD-17-0157.1.

Valcke, S., 2013: The OASIS3 coupler: A European climate modelling community software. Geosci. Model Dev., 6, 373-388, https:// doi.org/10.5194/gmd-6-373-2013.

Vellinga, M., D. Copsey, T. Graham, S. Milton, and T. Johns, 2020: Evaluating benefits of two-way ocean-atmosphere coupling for global NWP forecasts. Wea. Forecasting, 35, 2127-2144, https://doi.org/10.1175/WAF-D-20-0035.1.

Walters, D., and Coauthors, 2011: The Met Office Unified Model Global Atmosphere 3.0/3.1 and JULES Global Land 3.0/3.1 configurations. Geosci. Model Dev., 4, 919-941, https://doi.org/ 10.5194/gmd-4-919-2011.

— - and Coauthors, 2017: The Met Office Unified Model Global Atmosphere 6.0/6.1 and JULES Global Land 6.0/6.1 configurations. Geosci. Model Dev., 10, 1487-1520, https://doi.org/ 10.5194/gmd-10-1487-2017.

Williams, K., and Coauthors, 2013: The transpose-AMIP II experiment and its application to the understanding of Southern Ocean cloud biases in climate models. J. Climate, 26, 32583274, https://doi.org/10.1175/JCLI-D-12-00429.1.

— 2.0 (GC2) configuration. Geosci. Model Dev., 8, 1509-1524, https://doi.org/10.5194/gmd-8-1509-2015.

Williamson, D. L., and Coauthors, 2005: Moisture and temperature balances at the atmospheric radiation measurement southern Great Plains site in forecasts with the Community Atmosphere Model (CAM2). J. Geophys. Res., 110, D15S16, https://doi.org/ 10.1029/2004JD005109. 